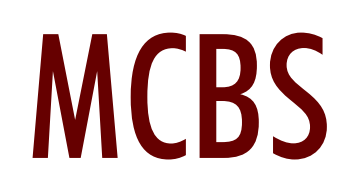

Mol Cell Biomed Sci. 2021; 5(2): 88-92

DOI: $10.21705 /$ mcbs.v5i2.197

\title{
Interleukin-1A May Illuminate Differential Effects of the Retinal Artery Caliber in HIV Patients
}

\author{
Lukman Edwar ${ }^{1}$, Ibnu Agus Ariyanto², Selita Agnes Tanudjaja ${ }^{3}$, Ratna Sitompul ${ }^{1}$, Silvia Lee ${ }^{4}$, \\ Patricia Price ${ }^{3,4}$ \\ ${ }^{1}$ Department of Ophthalmology, Faculty of Medicine, Universitas Indonesia, Jakarta, Indonesia \\ ${ }^{2}$ Virology and Cancer Pathobiology Research Center, Universitas Indonesia, Jakarta, Indonesia \\ ${ }^{3}$ School of Population Health, Curtin University, Bentley, Australia \\ ${ }^{4}$ School of Pharmacy \& Biomedical Science, Curtin University, Bentley, Australia
}

Background: Retinal artery caliber (RAC) is narrower in human immunodeficiency virus (HIV)-infected patients beginning antiretroviral therapy (ART). We aimed to assess associations between variations in genes encoding inflammatory mediators and natural killer receptors and retinal artery caliber (RAC) in HIV patients beginning ART.

Materials and Methods: Seventy-nine HIV positive patients beginning ART with less than 200 cluster of differentiation (CD) $4 \mathrm{~T}$-cells/ $\mu \mathrm{L}$ were recruited. Examinations were performed before ART (V0) and at months 3, 6 and 12 (V3, V6, V12). The study was approved by ethics committees and informed consent was obtained from each subject.

Results: Right and left RAC of the HIV patients were narrower than healthy controls ( $p=0.016$ for right RAC) and narrowed further on ART, but demographic associations with the right and left RAC were not identical. Here we show that polymorphisms in genes encoding NK receptors or TNF activity had no significant impact, but right RAC was associated with carriage of allele 2 at IL1A+4845 ( $p=0.037$ after 12 months on ART).

Conclusion: Overall the paradoxical reduction in the RAC in HIV patients responding to ART was not modified by genotypes known to affect NK cell function or TNF responses, but IL1A genotype may modify the decline in the right RAC.

Keywords: anti-retroviral therapy, CMV, HIV, IL1A, retinal artery caliber

\section{Introduction}

Microvascular disease is a common complications that affects the eyes in human immunodeficiency virus (HIV) patients, and can impair visual function as well., ${ }^{1,2}$ We have shown that retinal artery caliber (RAC) is narrower in HIVinfected patients beginning antiretroviral therapy (ART) than healthy controls and narrows further over time. ${ }^{3}$ Population- based studies link narrow RAC with higher current mean blood pressure, male sex, higher risk of chronic kidney disease and stroke mortality in persons with diabetes. ${ }^{4-7}$ Besides associations with systemic and cardiovascular disease, studies have identified links between narrow RAC with retinal vein occlusion and decreased retinal nerve fiber layer thickness compared to controls. ${ }^{8,9}$

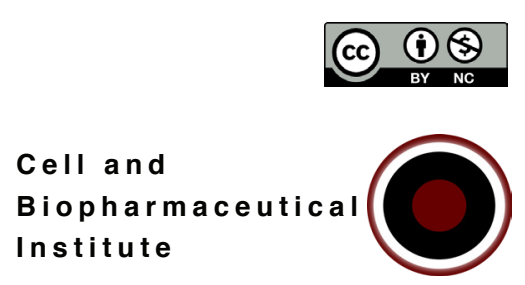


It now appears likely that cytomegalovirus (CMV)associated inflammation contributes to accelerated atherosclerosis in HIV-patients ${ }^{10}$, and so may influence RAC. However our longitudinal study identified a positive correlation between levels of antibody reactive with CMV immediate-early 1 (IE-1) antibody and the right RAC spanning several months on ART. ${ }^{3}$ This suggested a paradoxical and selective "protective" effect of CMV in the right eye. Different arterial pressure in the right and left eyes are possible because the right retinal artery is a branch of the right internal carotid artery to the brachiocephalic artery then aorta while the left retinal artery is a branch of the left internal carotid artery which originates directly from the aorta which make the left carotid artery may got exposed to a higher arterial pressure. ${ }^{11-13}$ However, this findings raised several questions regarding the underlying mechanisms in each eye.

Apart from their correlation with atherosclerosis, CMV infection can also stimulate an inflammatory response and their presence is linked with chronic inflammation in complex cycles of cause and effect. For example, natural killer $(\mathrm{NK})$ cells are important effectors during the host innate immune response to CMV infection. CMV and HIV can alter NK cells by modifying their receptor repertoire and function. ${ }^{14}$

Leukocyte immunoglobulin-like receptor-1 (LIR-1) is an inhibitory receptor that binds a several class I human leukocyte antigen (HLA) molecules, notably HLA-G, and is encoded by leukocyte immunoglobulin-like receptor subfamily B member 1 (LILRB 1$).{ }^{15}$ In Caucasian HIV patients, low nadir cluster of differentiation (CD)4 T-cell counts and a history of CMV disease were associated with heterozygosity at rs1061680 within LILRB1. ${ }^{16}$ A $14 \mathrm{bp}$ insertion/deletion in HLA-G gene (rs16375) affects the stability of HLA-G messenger RNA (mRNA) and HLA-G protein expression, and may influence susceptibility to active $\mathrm{CMV}$ infection. ${ }^{17} \mathrm{NKG} 2 \mathrm{C}$ is an activating receptor expressed on NK cells. Its expression in HIV patients is increased by their burden of CMV and reduced by a deletion mutation, with complex patterns seen in heterozygotes. ${ }^{18}$

Here we address variations in genes encoding inflammatory mediators and NK receptors, and assess which can affect RAC in each eye in HIV patients beginning ART. We align the data with the effects of genotype on CD4 T-cell counts and control of HIV replication.

\section{Materials and methods}

\section{Patients and Clinical Assessments}

Patients were assessed under the JakCCANDO project, based in Jakarta, a prospective cohort study of clinical and immunological responses to ART. We enrolled 79 HIV positive patients in 2013-2014 with $<200 \mathrm{CD} 4 \mathrm{~T}$-cells $/ \mu \mathrm{L}$ and no previous ART, and 63 healthy controls. The study was approved by Universitas Indonesia, Cipto Mangunkusumo General Hospital (No. 474/PT02.FK/ETIK/2012) and informed consent was obtained from each subject. We examined our patients from before ART (V0) and at months 3, 6 and 12 (V3, V6, V12). AmpliPrep/COBAS $®$ TaqMan $\AA$ HIV-1 Test (version 2.0) Roche ${ }^{\circledR}$ (Rotkreuz, Switzerland) were used to evaluate plasma HIV RNA loads and standard flow cytometric techniques to evaluate CD4 T-cell count.

\section{Eye Examination and RAC measurement}

Anterior segments and posterior segments of the eyes were examined with a standard slit-lamp biomicroscope and indirect funduscopy. Fundus photos were taken with a KOWA ${ }^{\circledR}$ VX-10 (Tokyo, Japan), and Nikon ${ }^{\circledR}$ 70s 6 megapixel camera (Tokyo, Japan), 30 minutes after instillation of $1 \%$ tropicamide. Areas selected for measurement were free of branching blood vessels through a region 0.5 to 1.0 disc diameters from the optic disc margin.19 RAC was measured with Image J software (http://rsbweb.nih.gov/ij/) by two trained doctors masked to patient names. Guideline for measuring RAC were used to minized bias between two doctors. Ten sites in one eye were analyzed by each trained doctor and 20 measurements in averaged. A $<10 \%$ standard deviation was found and notation was in pixels.

\section{Polymerase Chain Reaction (PCR)}

DNA was purified from saliva or buffy coats (Favorgen Biotech, Ping-Tung, Taiwan) and genotyped using TaqMan FAM or VIC-labeled probes; CD16 (rs396991), LIRB1 (rs1061680), IL12B 3'UTR (rs3212227), IL1A+4845 (rs17561), TNF-1031 (rs1799964), TNF-308 (rs1800629) and Universal PCR Master Mix (Applied Biosystems, Foster City, CA). ${ }^{16}$ A $16 \mathrm{~kb}$ deletion in exon 6 of $\mathrm{NKG} 2 \mathrm{C}$ was detected by PCR amplification $\left(96^{\circ} \mathrm{C}\right.$ for $5 \mathrm{~min}$ followed by 35 cycles of $96^{\circ} \mathrm{C}$ for $30 \mathrm{~s}, 57^{\circ} \mathrm{C}$ for $30 \mathrm{~s}$ and $72^{\circ} \mathrm{C}$ for $40 \mathrm{~s}$ ). A $14 \mathrm{bp}$ deletion in HLA-G was identified by PCR amplification $\left[95^{\circ} \mathrm{C}\right.$ for $5 \mathrm{~min}$ followed by 35 cycles of $95^{\circ} \mathrm{C}$ for $20 \mathrm{~s}, 60^{\circ} \mathrm{C}$ for $30 \mathrm{~s}$ and $72^{\circ} \mathrm{C}$ for $\left.30 \mathrm{~s}\right] .{ }^{20}$ 


\section{Statistical Analyses}

Associations between RAC and minor alleles predictors are presented as a median value and analyzed using simple linear regressions using Stata SE 14.2 (StataCorp LP, College Station, TX, USA). Minor allele frequencies were then included in a multivariable model with stepwise regression procedures to achieve optimal models predicting left and right RAC. The procedure was repeated with demographic variables included.

\section{Results}

HIV patients (male 54; female 25) and healthy controls (male 38; female 25) were matched by gender and age [median (range) age: 31 (19-48) vs. 30 (18-46) years] (Table 1). HIV patients recorded median (range) CD4 T-cell counts of 62 (2-99), 181 (7-601), 201 (6-516) and 284 (44-763) cells/ $\mu \mathrm{L}$, at V0, V3, V6 and V12, respectively (Table 2). No patients had detectable pathologies in their eyes at V12, including opportunistic infections.

Before ART, right and left RAC of the HIV patients were narrower than those of healthy controls [13.41(9.7616.77) vs. 14.71(12.30-17.41) pixels, $p=0.016$ for right RAC; 13.57 (7.84-17.43) vs. 14.65 (12.08-16.81) pixels, $p=0.005$ for left RAC]. Calibers recorded in the right and left eyes were similar in HIV patients at all times $(p=0.26$ $0.89)$ and in healthy controls $(p=0.82)$. RAC declined on ART yielding values of $12.16(8.26-16.14)$ at V3, 11.70 $(9.06-15.77)$ at V6 and $11.49(7.92-15.35)$ at V12 for the right eye.

No genotypes affected the left RAC at V6 or V12 (Table 3) when assessed individually by regression analyses. When all genotype variables were included followed by stepwise removal, the best model retained LILRB1 and $C D 16$ (adjusted $\mathrm{R}^{2}=0.0176, p=0.297$ ) and was inferior to the model derived with LILRB1 alone (adjusted $\mathrm{R}^{2}=0.035$,
Table 1. The demographic characteristics of study participants.

\begin{tabular}{lcc}
\hline Variable & $\begin{array}{c}\text { JAKCCANDO } \\
\text { HIV Patients } \\
(\mathbf{n = 7 9 )}\end{array}$ & $\begin{array}{c}\text { Healthy Controls } \\
(\mathbf{n}=\mathbf{6 3})\end{array}$ \\
\hline Gender & & \\
$\quad$ Male & 54 & 38 \\
$\quad$ Female & 25 & 25 \\
Age & & \\
$\quad$ Median & 31 & 18 \\
$\quad$ Range & $19-48$ & $18-46$ \\
\hline
\end{tabular}

$p=0.137$ ). The inclusion of demographic factors (age, gender, smoking, taking alcohol, opportunistic infections: pulmonary tuberculosis) and other measures (CMV IE-1 antibody, CMV lysate antibody, CD4 T-cell counts, plasma HIV RNA, carotid intima-media thickness (cIMT) and c-reactive protein (CRP)) did not improve any model.

Examination of right RAC revealed associations with carriage of allele 2 at IL1A +4845 ( $p=0.059$ at V6 and $p=0.037$ at $\mathrm{V} 12$ ). The stepwise regression beginning with all genotypes included, retained IL1A in the final model as the single significant predictor of right RAC at V12 (adjusted $\mathrm{R}^{2}=0.059, p=0.037$ ). Thus, IL1A can explain $5.9 \%$ of right RAC variation at V12. The model improved a little following adjustment for consuming alcohol, smoking, and plasma HIV RNA (adjusted $\mathrm{R}^{2}=0.137, p=0.041$ ). At V6, the optimal model derived without demographic factors retained IL1A but was not significant (adjusted $\mathrm{R}^{2}=0.041$, $p=0.059$ ). When all the demographic factors were included in the multivariable regression, IL1A, age, gender and CRP were retained as the optimal model (adjusted $\mathrm{R}^{2}=0.060$, $p=0.108$ ) but did not achieve significance.

Table 2. CD4 T-cell counts before ART (V0) and at monrths 3, 6 and 12 (V3, V6, V12).

\begin{tabular}{lcccc}
\hline $\begin{array}{c}\text { CD4 T-cell Counts } \\
\text { (cells/ } \boldsymbol{\mu l )}\end{array}$ & V0 & V3 & V6 & V12 \\
\hline Minimum & 2 & 7 & 6 & 44 \\
Median & 62 & 181 & 201 & 284 \\
Maximum & 199 & 601 & 516 & 763 \\
\hline
\end{tabular}


Table 3. IL1A genotype may affect right RAC after 12 months on ART.

\begin{tabular}{|c|c|c|c|c|c|c|c|c|c|}
\hline & \multirow[b]{2}{*}{ Gene } & \multicolumn{4}{|c|}{ Right RAC } & \multicolumn{4}{|c|}{ Left RAC } \\
\hline & & $\begin{array}{c}\text { Caliber } \\
\text { (pixels)* }\end{array}$ & & & Adjusted $R^{2}$ & $\begin{array}{c}\text { Caliber } \\
\text { (pixels)* }^{*}\end{array}$ & & & Adjusted $R^{2}$ \\
\hline \multirow[t]{3}{*}{ CD16 } & AA & 11.75 & reference & & & 12.23 & reference & & \\
\hline & $\mathrm{AC}$ & 11.49 & 0.649 & 0.48 & -0.009 & 11.52 & 0.362 & 0.517 & -0.012 \\
\hline & $\mathrm{CC}$ & 11.04 & 0.243 & & & 11.92 & 0.277 & & \\
\hline \multirow[t]{3}{*}{ LILRB1 } & $\mathrm{TT}$ & 11.68 & reference & & & 11.14 & reference & & \\
\hline & $\mathrm{TC}$ & 11.34 & 0.073 & 0.198 & 0.023 & 11.56 & 0.068 & 0.137 & 0.035 \\
\hline & $\mathrm{CC}$ & 11.74 & 0.229 & & & 12.1 & 0.071 & & \\
\hline \multirow[t]{2}{*}{ NKG2C } & $+/+$ & 11.5 & reference & 0776 & -0016 & 11.63 & reference & 054 & -0011 \\
\hline & $+/-$ & 11.31 & 0.776 & 0.110 & -0.010 & 12.08 & 0.54 & 0.34 & -0.011 \\
\hline \multirow[t]{3}{*}{ HLA-G } & $-14 b p /-14 b p$ & 11.35 & reference & & & 11.48 & reference & & \\
\hline & $-14 b p /+14 b p$ & 11.71 & 0.221 & 0.196 & 0.023 & 11.77 & 0.195 & 0.403 & -0.003 \\
\hline & $+14 b p /+14 b p$ & 11.3 & 0.108 & & & 12.52 & 0.998 & & \\
\hline \multirow[t]{2}{*}{ IL1A+4845 } & GG & 11.48 & reference & 0.037 & 0.059 & 11.87 & reference & 0.957 & \multirow{2}{*}{-0.018} \\
\hline & GT & 12.85 & 0.037 & & & 11.42 & 0.957 & & \\
\hline \multirow[t]{3}{*}{ IL-12(3'UTR) } & $\mathrm{AA}$ & 11.64 & reference & 0.498 & -0.01 & 11.52 & reference & 0.914 & \multirow{3}{*}{-0.032} \\
\hline & $\mathrm{AC}$ & 11.34 & 0.262 & & & 11.82 & 0.766 & & \\
\hline & $\mathrm{CC}$ & 11.74 & 0.831 & & & 12.01 & 0.896 & & \\
\hline \multirow[t]{3}{*}{ TNF-1031 } & $\mathrm{TT}$ & 11.35 & reference & 0.065 & 0.061 & 11.82 & reference & 0.685 & \multirow{3}{*}{-0.021} \\
\hline & $\mathrm{TC}$ & 11.68 & 0.036 & & & 11.56 & 0.645 & & \\
\hline & $\mathrm{CC}$ & 11.1 & 0.522 & & & 11.44 & 0.522 & & \\
\hline \multirow[t]{2}{*}{ TNF-308 } & GG & 11.49 & reference & 0.495 & -0.009 & 11.82 & reference & 0.99 & \multirow{2}{*}{-0.017} \\
\hline & GA & 11.29 & 0.495 & & & 11.49 & 0.99 & & \\
\hline
\end{tabular}

*median values.

\section{Discussion}

We found no significant associations with polymorphisms affecting TNF or NK activity, but a polymorphism in the gene encoding IL-1 $\alpha$ affected the right RAC. IL1A genotypes have been investigated in Caucasians but few studies have investigated Asian populations. IL1A+4845 and IL1A-889 are in complete linkage disequilibrium in Caucasians ${ }^{21}$ and severe periodontal disease and elevated levels of IL-1 $\alpha$ in gingival crevicular fluid associated with IL1A-889*22 as did poor virological control in HIV patients receiving $\mathrm{ART}^{23} \mathrm{IL} 1 \mathrm{~A}+4845$ changes an alanine [allele 1 (G)] to serine [allele $2(\mathrm{~T})$ ] at position 114 of IL-1 $\alpha$. The role of IL- $1 \alpha$ in HIV replication is possible because IL- $1 \alpha$ can be cleaved to a $17 \mathrm{kDa}$ C-terminal fragment, which able to interact with IL-1 membrane receptors, and to a $16 \mathrm{kDa}$ $\mathrm{N}$-terminal domain that is affects cellular metabolism and induces apoptosis via their binding to RNA. Phosphorylation of serine or threonine residues near the active site enhances cleavage of the calpain, so a serine at position 114 could promote digestion. ${ }^{24}$ Here log HIV RNA levels at V12 was marginally higher in patients who carry IL1A $+4845 * 2$ (5.50 vs. 3.91; $p=0.105)$. These patients have lower right RAC and our time course shows that RAC declines on ART so patients with IL1A $+4845 * 2$ may have impaired viral clearance which in turn delays the decline in their RAC.

Deficiency of IL- $1 \alpha$ has been reported to afford more protection from atherosclerosis. ${ }^{25}$ IL-1 activates endothelial cells and smooth muscle cells hence causing enhanced expression of leukocyte adhesion molecules, clotting factors and inhibitors of fibrinolysis, and chemokines, as well as increased proliferation of smooth muscle cells, resulting in larger atherosclerotic lesions with more macrophage cells in the lesion. ${ }^{26}$ In ocular findings, IL- $1 \alpha$ damaged retinal pigment epithelium (RPE) by secreting pro-inflammatory cytokines. ${ }^{27}$ IL-1 $\alpha$ also found higher in Age-Related Macular Degeneration (AMD) patients if compared with healthy controls. ${ }^{28}$ However associations between alleles of IL1A and microvascular changes have not been fully understood. Although we followed up until 12 months of study, our findings are limited by the fact that we were only able to enroll 79 patients. 


\section{Conclusion}

Our study concluded that the paradoxical reduction in the caliber of retinal vessels in HIV patients responding to ART was not modified by genotypes known to modify NK cell function or TNF responses, but ILIA genotypes warrant further study. We suggested to a study that measures the IL$1 \alpha$ phenotype and compares it with its genotype affecting changes on retinal artery caliber.

\section{References}

1. Kozak I, McCutchan JA, Freeman WR. HIV-Associated Infections. In: Stephen R, Charles W, Andrew S, editors. Retina. 5th Edition. Philadelphia: Elsevier. 2012. p. 1441-72.

2. Tsen CL, Chen SC, Chen YS, Sheu SJ. Uveitis as an initial manifestation of acquired immunodeficiency syndrome. Int J STD AIDS. 2017; 28(12): 1224-8.

3. Edwar L, Karim B, Wijaya I, Ariyanto I, Tanudjaja SA, Estiasari R, et al. Factors affecting the health of retinal vessels in HIV patients beginning anti-retroviral therapy. AIDS Res Hum Retroviruses. 2019; 35(6): 529-35.

4. Sun C, Liew G, Wang JJ, Mitchell P, Saw SM, Aung T, et al. Retinal vascular caliber, blood pressure, and cardiovascular risk factors in an asian population: The Singapore malay eye study. Investig Ophthalmol Vis Sci. 2008; 49(5): 1784-90.

5. Yau JWY, Xie J, Kawasaki R, Kramer H, Shlipak M, Klein R, et al. Retinal arteriolar narrowing and subsequent development of CKD stage 3: The multi-ethnic study of atherosclerosis (MESA). Am J Kidney Dis. 2011; 58(1): 39-46.

6. Sabanayagam C, Tai ES, Shankar A, Lee J, Sun C, Wong TY. Retinal arteriolar narrowing increases the likelihood of chronic kidney disease in hypertension. J Hypertens. 2009; 27(11): 2209-17.

7. Klein R, Klein BEK, Moss SE, Wong TY. Retinal vessel caliber and microvascular and macrovascular disease in type 2 diabetes. XXI: The Wisconsin Epidemiologic Study of Diabetic Retinopathy. Ophthalmology. 2007; 114(10): 1884-92.

8. Youm DJ, Ha MM, Chang Y, Song SJ. Retinal vessel caliber and risk factors for branch retinal vein occlusion. Curr Eye Res. 2012; 37(4): 334-8.

9. Chang M, Yoo C, Kim SW, Kim YY. Retinal vessel diameter, retinal nerve fiber layer thickness, and intraocular pressure in Korean patients with normal-tension glaucoma. Am J Ophthalmol. 2011; 151(1): 100-5.

10. Hsue PY, Hunt PW, Sinclair E, Bredt B, Franklin A, Killian M, et al. Increased carotid intima-media thickness in HIV patients is associated with increased cytomegalovirus-specific T-cell responses. AIDS. 2006; 20(18): 2275-83.

11. Selwaness M, Van Den Bouwhuijsen Q, Van Onkelen RS, Hofman A, Franco OH, Lugt AVD, et al. Atherosclerotic plaque in the left carotid artery is more vulnerable than in the right. Stroke. 2014; 45(11): 3226-30.

12. Ionescu AM, Carciumaru N, Chirila S. Carotid artery disease - left vs right. ARS Medica Tomitana. 2017; 22(3): 169-73.

13. Loizou CP, Nicolaides A, Kyriacou E, Georghiou N, Griffin M, Pattichis CS. A comparison of ultrasound intima-media thickness measurements of the left and right common carotid artery.
IEEE J Transl Eng Heal Med. 2015; 3: 1990410. doi: 10.1109/ bibe. 2013.6701666

14. Muntasell A, Vilches C, Angulo A, López-Botet M. Adaptive reconfiguration of the human NK-cell compartment in response to cytomegalovirus: A different perspective of the host-pathogen interaction. Eur J Immunol. 2013; 43(5): 1133-41

15. Davidson CL, Li NL, Burshtyn DN. LILRB1 polymorphism and surface phenotypes of natural killer cells. Hum Immunol. 2010; 71(10): 942-9.

16. Affandi JS, Aghafar ZKA, Rodriguez B, Lederman MM, Burrows $\mathrm{S}$, Senitzer $\mathrm{D}$, et al. Can immune-related genotypes illuminate the immunopathogenesis of cytomegalovirus disease in human immunodeficiency virus-infected patients? Hum Immunol. 2012; 73(2): 168-74.

17. Zheng XQ, Zhu F, Shi WW, Lin A, Yan WH. The HLA-G 14 bp insertion/deletion polymorphism is a putative susceptible factor for active human cytomegalovirus infection in children. Tissue Antigens. 2009; 74(4): 317-21.

18. Ariyanto IA, Estiasari R, Edwar L, Makwana N, Lee S, Price P. Characterization of natural killer cells in HIV patients beginning therapy with a high burden of cytomegalovirus. Immunol Invest. 2018; 48(4): 345-54.

19. Liew G, Wang JJ, Mitchell P, Wong TY. Retinal vascular imaging: a new tool in microvascular disease research. Circ Cardiovasc Imaging. 2008; 1(2): 156-61.

20. Waters S, Lee S, Affandi JS, Irish A, Price P. The effect of genetic variants affecting NK cell function on cardiovascular health and the burden of CMV. Hum Immunol. 2017; 78(11-12): 747-51.

21. Karimbux NY, Saraiya VM, Elangovan S, Allareddy V, Kinnunen T, Kornman KS, et al. Interleukin-1 gene polymorphisms and chronic periodontitis in adult whites: a systematic review and meta-analysis. J Periodontol. 2012; 83(11): 1407-19.

22. Shirodaria S, Smith J, McKay IJ, Kennett CN, Hughes FJ Polymorphisms in the IL-1A gene are correlated with levels of interleukin-1 $\alpha$ protein in gingival crevicular fluid of teeth with severe periodontal disease. J Dent Res. 2009; 79(11): 1864-9.

23. Price P, James I, Fernandez S, French MA. Alleles of the gene encoding IL- $1 \alpha$ may predict control of plasma viraemia in HIV-1 patients on highly active antiretroviral therapy. AIDS. 2004; 18(11): 1495-501.

24. Kawaguchi Y, Tochimoto A, Hara M, Kawamoto M, Sugiura T, Saito $\mathrm{S}$, et al. Contribution of single nucleotide polymorphisms of the IL1A gene to the cleavage of precursor IL- $1 \alpha$ and its transcription activity. Immunogenetics. 2007; 59(6): 441-8.

25. Kamari Y, Werman-Venkert R, Shaish A, Werman A, Harari A, Gonen $\mathrm{A}$, et al. Differential role and tissue specifitiy of interleukin-1A gene expression in atherogenesis and lipid metabolism. Atherosclerosis. 2003; 195(1): 31-8.

26. Isoda K, Sawada S, Ishigami N, Matsuki T, Miyazaki K, Kusuhara $\mathrm{M}$, et al. Lack of interleukin-1 receptor antagonist modulates plaque composition in apolipoprotein e-deficient mice. Arterioscler Thromb Vasc Biol. 2004; 24(6): 1068-73.

27. Wooff Y, Man SM, Aggio-Bruce R, Natoli R, Fernando N. IL-1 familly members mediate cell death, inflammation and angigenesis in retinal degenerative disease. Front Immunol. 2019; 10:1618. doi: 10.3389/fimmu.2019.01618.

28. Nassar K, Grisanti S, Elfar E, Luke J, Luke M, Grisanti S. Serum cytokines as biomarkers for age-related macular degeneration. Graefes Arch Clin Exp Ophthalmol. 2015; 253(5): 699-704. 